[Aus dem hygienischen Institut der Universität Breslau.]

\author{
Ueber die Daner der Lebensfähigkeit \\ von Tuberkelbacillen an flugfähigen Stäubchen. \\ Von \\ Dr. Fritz Kirstein, \\ früherem I. Assistenten des Instituts, z. Z. Kreisarzt in Olpe 1/W.
}

Dass der Tuberkelbacillus verstäubbar ist und dass Infectionen durch verstäubtes Sputum möglich sind, ist von einer Reihe von Schülern Flügge's und Cornet bewiesen. Um ein Bild von den Infectionschancen durch trockeneu Sputumstaub zu gewinnen, hat bekanntlich zuerst Cornet ${ }^{1}$ Staubproben aus Krankensälen, Privatwohnungen von Phthisikern auf Tuberkelbacillen untersucht und recht erhebliche Zahlen gefunden: in Krankenbäusern 47.6 Procent, in Irrenanstalten 17.6 Procent und in Privatwohnungen von Phthisikern 43.6 Procent positive Resultate. Durch ausgedehnte und exakte Nachprüfungen von Heymann ${ }^{2}$ hat sich jedoch gezeigt, dass Cornet bei seinen Versuchen keineswegs immer flug fähigen Staub vor sich hatte, der für das Zustandekommen einer Luftinfection dureh Sputumstaub in Betracht kommt.

Unter Vermeidung der Versuchsfehler Cornet's fand Heymann in Krankenhäusern und in Privatzimmern von Phthisikern nur 8 Procent positive Proben.

Demnach ist die Infectionsgefahr in derartigen Räumen dureh trockenen flugfähigen Sputumstaub doch bedeutend geringer, wie es nach den Untersuchungen von Cornet scheinen könnte.

${ }^{1}$ Cornet, Diese Zeitschrift. 1883. Bd. V,

${ }^{2}$ Heymann, Ebenda. 1899. Bd. XXX. 
Neuerdings suchte nun Gotschlich ${ }^{1}$ über die Infectionschancen in Räumen, welche dem öffentlichen Verkehre dienen und in welchen sich gelegentlich auch Phthisiker aufhalten, Aufschluss zu gewinnen. Die Versuche wurden nach Analogie derjenigen von Heymann unter. sorgfältiger Auswahl der Entnahmestellen der Staubproben vorgenommen, sodass nur flugfähiger Staub zur Verwendung kam.

In 119 Staubproben von 15 verschiedenen Räumlichkeiten konnte jedoch Gotschlich kein einziges Mal Tuberkelbacillen nachweisen.

Die Infectionschancen scheinen demnach in derartigen Räumen (Wartesäle grosser Bahnhöfe u. dergl.) relativ geringe zu sein, jedenfalls zum Theil bedingt durch die hochgradige Verdünnung des ausgestreuten Virus. Andererseits ist $\mathrm{zu}$ bedenken, dass bei Gotschlich's Versuchen nur kleine Bruchtheile des vorhandenen Staubes zur Untersuchung kamen, und dass daher eine experimentelle Prüfung der Lebensdauer der Tuberkelbacillen in der Form feinster Stäubchen vielleicht ein zuverlässigeres Urtheil über die Grösse der Infectionsgefahr durch tuberkelbacillenhaltige Stäubchen gestattet.

In einer früheren Arbeit ${ }^{2}$ hatte ich die Beantwortung dieser Frage bereits ins Auge gefasst; jedoch habe ich damals aus äusseren Gründen nur orientierende Vorversuche mit Prodigiosusbacillen und Staphylokokken ausführen können.

Ich habe daher um so lieber eine Anregung des Herrn Geheimrath Flügge, diese Versuche wieder aufzunehmen, Folge gegeben.

Da vermuthlich die Lebensdauer der Tuberkelbacillen von der Qualität des als Vehikel dienenden Staubes nicht zum geringen Theil abhängig ist, wurden rerschiedene Methoden eingeschlagen, tuberkelbacillenbehaftete Stäubchen zu gewinnen.

Die Versuche zerfallen in 4 Kategorieen:

1. Versuche mit flugfähigem, mit feinsten tuberkelbacillenbaltigen Tröpfchen beladenem Actenstaub;

2. Versuche mit feinstem tuberkelbacillenhaltigen Sputumstaub;

3. Versuche mit feinsten tuberkelbacillenbehafteten Kleiderfasern;

4. Versuche mit feinstem tuberkelbacillenbehafteten Strassenstaub.

1 Gotschlich, Die Verbreitung der Tuberkelbacillen im Staub von Räumen mit starkem Menschenverkehr. Inang.-Diss. Breslau 1903.

${ }^{2}$ Kirstein, Diese Zeitschrift. 1902. Bd. XXXIX. 
Den Versuchen sub 1. lag der Gedanke zu Grunde festzastellen, ob und wie lange von feinstem flugfähigen Staube, auf den von Phthisikern feinste tuberkelbacillenhaltige Tröpfchen ausgesät werden, nach der Ausstreuung der letzteren eine Infectionsgefahr zu befürchten ist.

Bei der Anstellung der Versuche sub 1. wurde folgendermaassen vorgegangen:

Actenstaub von hiesigen Gerichten wurde fein gesiebt. Der feinste Antheil dieses Staubes kam in eine Sangflasche. Von hier aus wurde der Staub rermittelst eines Blasebalges durch eine zweite leere Saugflasche und von da endlich in eine Glasglocke getrieben, welche auf eine Mattscheibe luftdicht aufgesetzt war. Unter der Glasglocke befand sich eine runde Scheibe, welche 12 bis 14 gewöhnliche, gereinigte Objectträger trug. Diese waren dazu bestimmt, den in der angegebenen Weise in seine feinsten Bestandtheile zerlegten Staub aufzufangen. Es wurde nun solange Staub in die Glasflasche übergetrieben, bis die ausgelegten Objectträger vollkommen mit dem Staube bedeckt waren. Auf diese Weise wurden nacheinander 40 Objectträger mit einer dichten Lage feinsten Staubes bedeckt.

Es blieb noch übrig, die so beschickten Objectträger einem feinsten tuberkelbacillenhaltigen Spray auszusetzen.

$\mathrm{Zu}$ diesem $\mathrm{Zwecke} \mathrm{kamen} \mathrm{die} \mathrm{mit} \mathrm{den} \mathrm{Objectträgern} \mathrm{beladenen} \mathrm{Scheiben}$ in einen Glaskasten von $70^{\mathrm{cm}}$ Höhe, $60 \mathrm{~cm}$ Breite und $50 \mathrm{~cm}$ Tiefe. In der Mitte einer Seitenwand befand sich eine Oeffnung, durch welche der tuberkelbacillenhaltige Spray durch ein Glasrohr eingeführt wurde.

In einer gegenüberliegenden Ecke befand sich eine zweite Oeffnung, durch welche die eingetriebene, mit feinsten Tröpfehen beladene Luft abströmen konnte. Letztere gelangte mittelst eines durch einen Fensterrahmen geführten Glasrohrs direct ins Freie.

Auf dem Boden. des Kastens waren ausser den Scheiben mit den staubbeladenen Objectträgern noch einige Deckgläschen deponirt, welche zur Controle der Art und der Zahl der aufgefallenen tuberkelbacillenhaltigen Tröpfehen dienten.

Der erste derartige Versuch wurde am 10. XII. 02 vorgenommen.

Zur Versprayung gelangte ein tuberculöses Sputum (Gaffky's Tabelle Nr. VIII). Dasselbe wurde mit 3 Theilen Wasser verdünnt und durch Schütteln mit Quarzsand in eine homogene Masse verwandelt.

Nachdem noch zwei Meerschweinchen zur Controle mit der Sprayflüssigkeit inficirt worden waren, wurde die Verspritzung mit dem Buchner'schen Zerstäuber vorgenommen. Der tuberkelbacillenhaltige Spray wurde ron letzterem direct ohne Schlauchrerbindung in den Kasten geleitet. Die auf diese Weise producirten Tröpfchen sind von solcher 
Feinheit, dass ihr Einströmen höchstens als schwacher Nebel wahrgenommen wird.

Es wurden auf diese Weise einige Cubikcentimeter der Sputumflüssigkeit rerspritzt.

Nach Beendigung der Versprayung zeigten sich die Controldeckgläschen mit vereinzelten Tuberkelbacillen gleichmässig bedeckt, so zwar, dass auf 20 bis 30 Gesichtsfelder 1 Tuberkelbacillus kam.

Die aufgefallenen Tröpfchen beherbergten meist nur einen, seltenmehrere Bacillen, und zwar waren die feinsten Tröpfchen so klein, dass ihr Durchmesser durch die Länge des verspritzten Tuberkelbacillus dargestellt wurde. An ihn schloss sich die blau gegengefärbte Tröpfchenmasse als kreisfōrmige Fläche an.

Zur Feststellung der Dauer der Lebensfähigktit der an dem feinsten Staub haftenden Tuberkelbacillen wurde in zweifacher Weise verfahren.

Einmal wurde in bestimmten Intervallen nach Besprayung des Staubes mit tuberkelbacillenhaltigen Tröpfchen derselbe ohne weiteres auf lebensfähige Tuberkelbacillen hin untersucht.

In einer zweiten Versuchsreihe wurde der in dieser Weise inficirte Staub in denselben Intervallen daraufhin geprüft, ob seine flugfähigen Bestandteile nach Fortführung durch Luftströme ron bekannter Stärke noch lebensfähige Tuberkelbacillen trügen.

Bei dem ersten Versuche wurden in Abständen von 2, 3, 5 und 8 Tagen die staubbedeckten besprayten Objectträger, welche - wie in allen übrigen Versuchen - während der ganzen Versuchszeit in dem Glaskasten dem diffusen Tageslichte ausgesetzt waren, in folgender Weise untersucht:

Zunächst wurden an jedem Termine je 2 Objectträger mit $15 \mathrm{~cm}$ Nährbrühe abgeschwemmt und von der schwärzlich aussehenden Flüssigkeit je $5 \mathrm{cem}$ einem Meerschweinchen intraperitoneal einverleibt.

Zur Prüfung der Lebensdauer der Tuberkelbacillen an den flugfähigen Stäubchen, welche jeweils an denselben Terminen vorgenommen wurde, war eine besondere Versuchsanordnung erforderlich, die in folgender Weise getroffen wurde.

Dieselbe schloss sich an die schon von Neisser ${ }^{1}$ getroffenen Versuchsanordnung an.

In einer Flasche $b$ wurde der inficirte Staub von den Objectträgern abgeschüttelt und von hier aus durch einen Luftstrom von bekannter Stärke in eine senkrecht stehende Blechröhre c entgegen der Schwere weitergeführt. Die nachströmende Luft musste zuvor ( $v g l . F_{1} g .1$ ) die Flasche $a$, eine Saugflasche, passiren, in deren Hals eine zum Schutze

${ }^{1}$ Neisser, Diese Zeitschrift. 1898. Bd. XXV̀II. 
gegen Verunreinigungen mit Watte versehene Glasröhre eingelassen war. Der inficirte Staub wurde in einer $15^{\mathrm{cem}}$ physiologischer Kochsalzlösung enthaltenden Waschflasche $d$ aufgefangen. An letztere schloss sich eine mit Schwefelsäure gefüllte Flasche $e$ an, welche etwa mitgerissene Tuberkel-

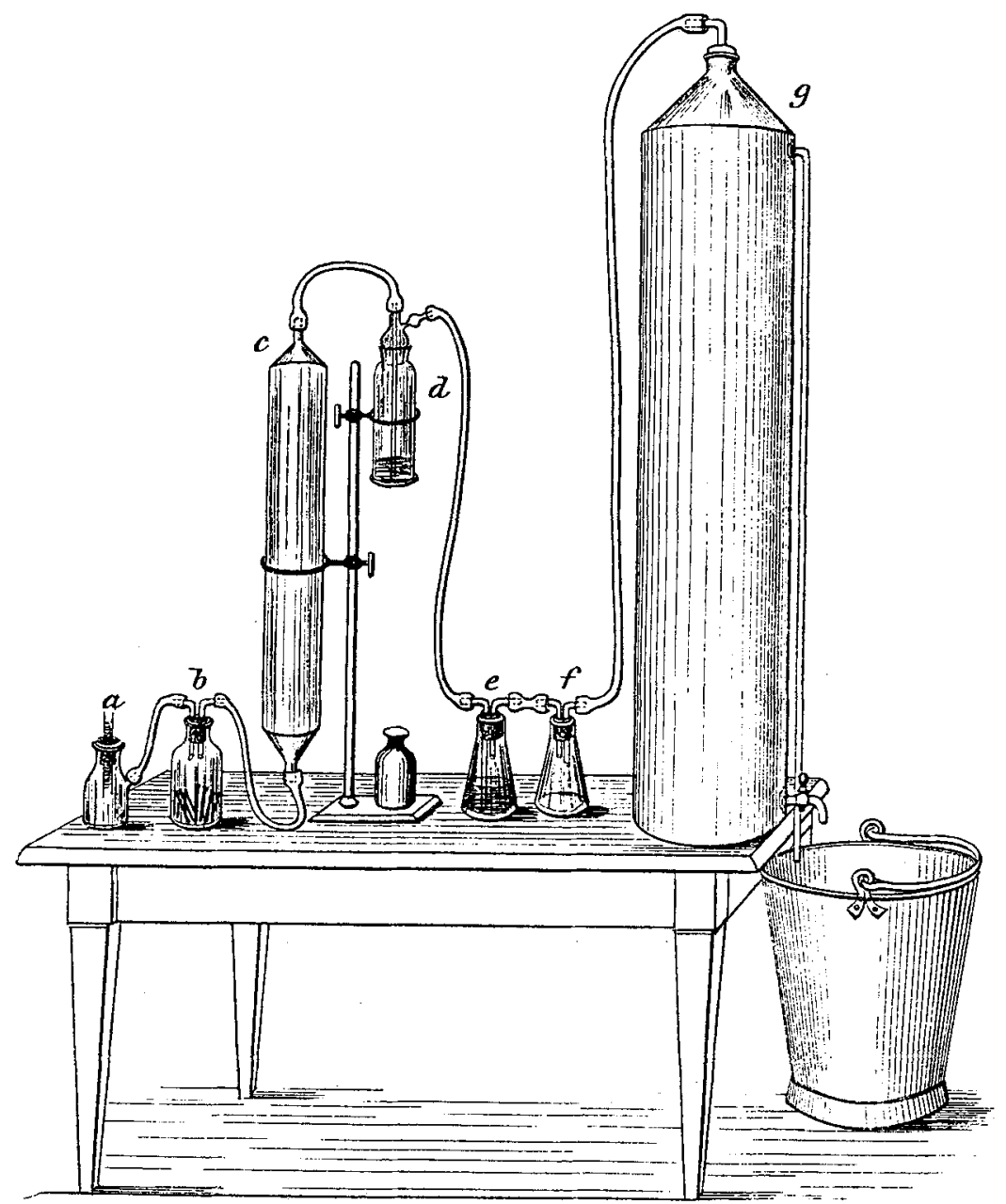

Fig. 1. Apparat zum Aufsaugen feinster flugfähiger Stäubchen.

$a$ Flasche für die nachströmende Luft, $b$ Schüttelflasche, $c$ Aspirationsröhre, $d$ Waschflasche, $e$ Flasche mit conc. Schwefelsäure, $f$ leere Flasche, $g$ Wassertharm.

bacillen abfangen sollte. Eine leere Flasche $f$ verband diese mit einem Wasserturme $g$. Durch entsprechende Stellung des Abflusshahnes desselben konnte die Geschwindigkeit des Luftstromes in der Röhre $c$ auf genaue Weise bestimmt werden. 
Die zum ersten Versuche verwendete Blechröhre war $1^{\mathrm{m}}$ lang und hatte einen Durchmesser von $4 \mathrm{~cm}$.

Die Geschwindigkeit des Luftstromes in der Röhre berechnet sich leicht aus der pro Secunde abfliessenden Wassermenge, geteilt durch den Querschnitt der Röhre.

Im ersten Versuche wurde die abfliessende Wassermenge so regulirt, dass in der Röhre eine Gesehwindigkeit des Luftstromes von $8^{\mathrm{cm}}$ pro Secunde den Staub transportirte. Es wurde also ein ziemlich starker Luftstrom gewählt.

Die schon nach kurzer Zeit durch den aspirirten Stanb trübe gewordene Waschflüssigkeit wurde nach Beendigung der Aspiration auf 3 Meerschweinchen durch intraperitoneale Injection vertheilt.

Das Ergebnis des ersten Versuchs ist aus der Tabelle I ersichtlich.

Aus derselben geht hervor, dass die mit feinsten Tröpfchen an flugfähigen Stäubchen haftenden Tuberkelbacillen wenigstens 8 Tage lebensfähig bleiben, und zwar auch dann noch, weun die Stãubchen nach diesem Zeitpunkte durch stärkere Luftströme transportiert werden.

Der zweite derartige Versuch wurde in ganz analoger Weise mit geringen Abänderungen vorgenommen.

Es ist noch zu bemerken, dass bei diesem Versuche ein tuberculöses Sputum Gaffky's Tabelle Nr. IX nach entsprechender Verdünnung verwendet würde. Diesmal wurden 4 runde Glasscheiben, auf welchen sich je 13 dicht mit feinstem Aktenstaub bedeckte Objectträger befanden, dem Sputumspray am 9. I. 03 ausgesetzt. Es wurden in 6 Stunden in mühsamer Weise etwa $10 \mathrm{~cm}$ der Sputumflüssigkeit mit dem Buchner'schen Zerstäuber rerspritzt, aber mit dem Resultate, dass auf den an den verschiedensten Punkten in dem Kasten ausgelegten Controldeckgläschen in jedem Gesichtsfeld durchschnittlich 1 Tuberkelbacillus gezählt wurde, was auf eine sehr gleichmässige Vertheilung des Sprays in dem Kasten schliessen liess. Es fielen demnach auf einen Objectträger ca. $8000 \mathrm{Tu}$ berkelbacillen auf.

Die Untersuchung auf die Lebensfähigkeit der Tuberkelbacillen wurde in denselben Intervallen wie bei Versuch Nr. 1 vorgenommen, also nach 2, 3, 5 und 8 Tagen.

Auf der einen Seite wurden je 3 Objectträger mit $15^{\mathrm{cem}}$ Nährbrühe abgeschwemmt und die Spülfüssigkeit anf 3 Meerschweinchen intraperitoneal vertheilt. Andererseits wurden jeweils 10 Objectträger zur Aspiration des auf ihnen abgelagerten und besprayten Staubes rerwendet. Bei dem zweiten Versuch wurde die Aspiration derart eingerichtet, dass in der dem Staubtransporte dienenden Röhre eine Strömungsgeschwindigkeit zu Stande kam, welche den in ruhigen Zimmern meist vorhandenen Luftströmen von 


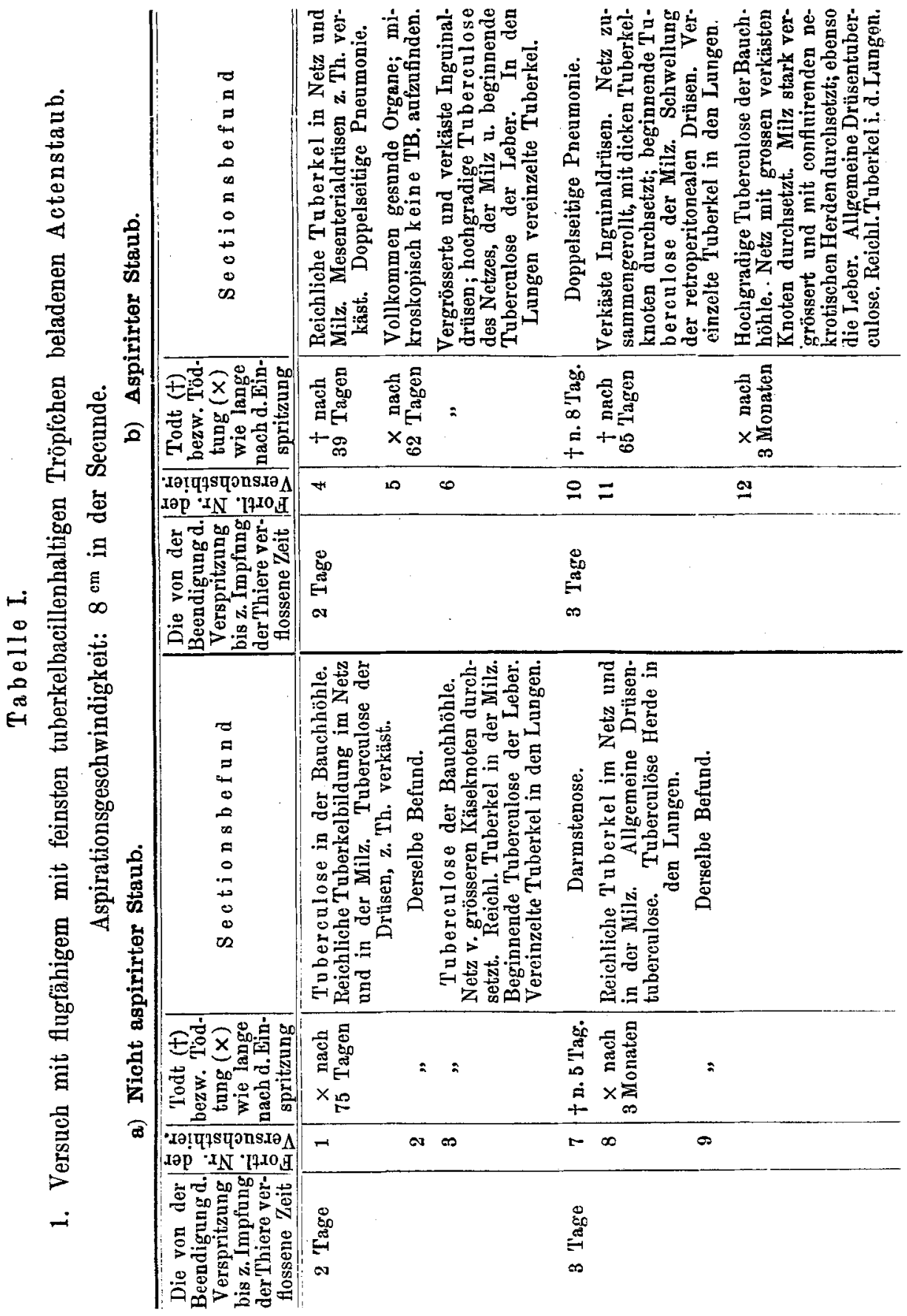



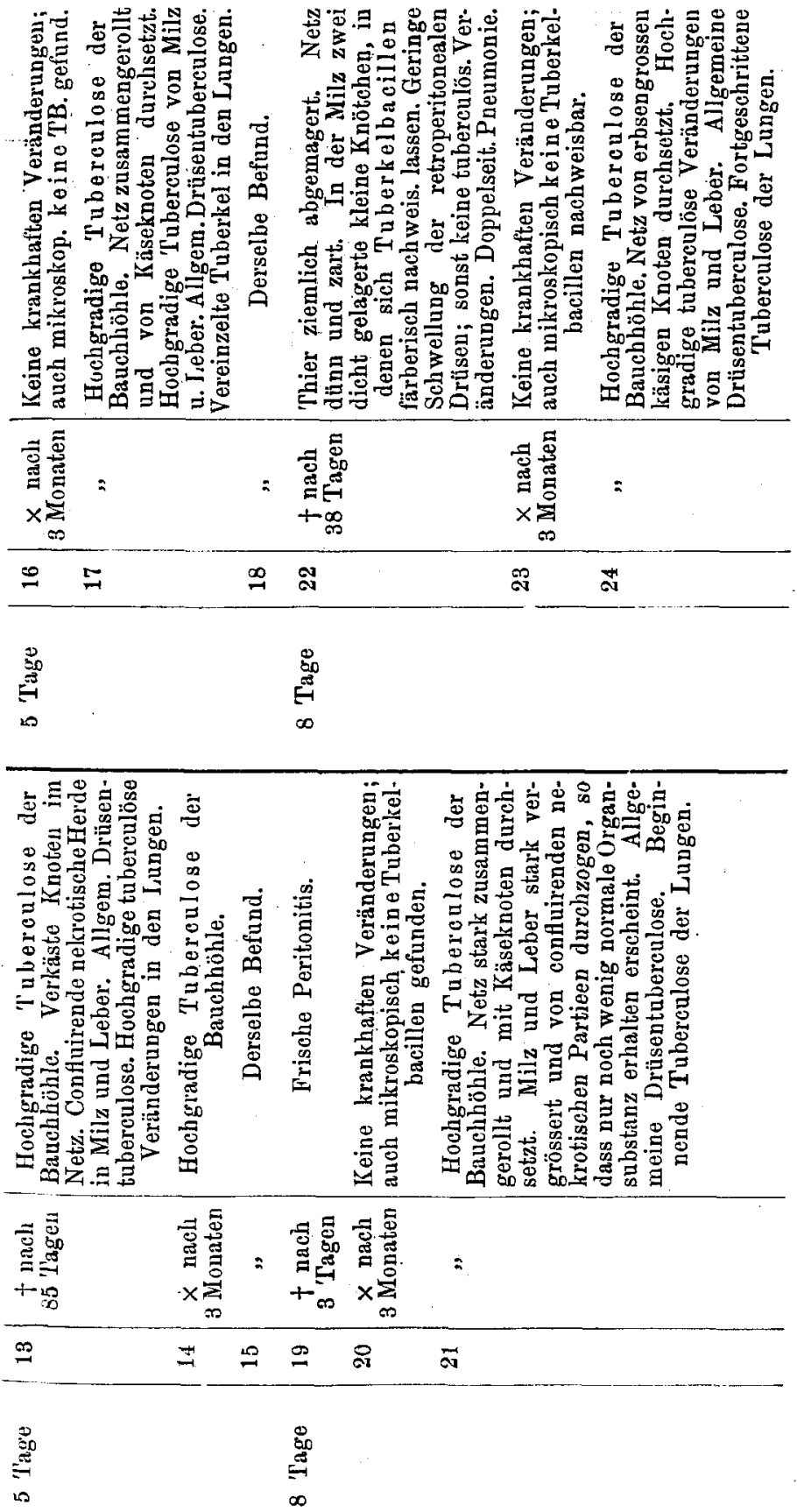

Zeitschr. f. Hygiene. L.

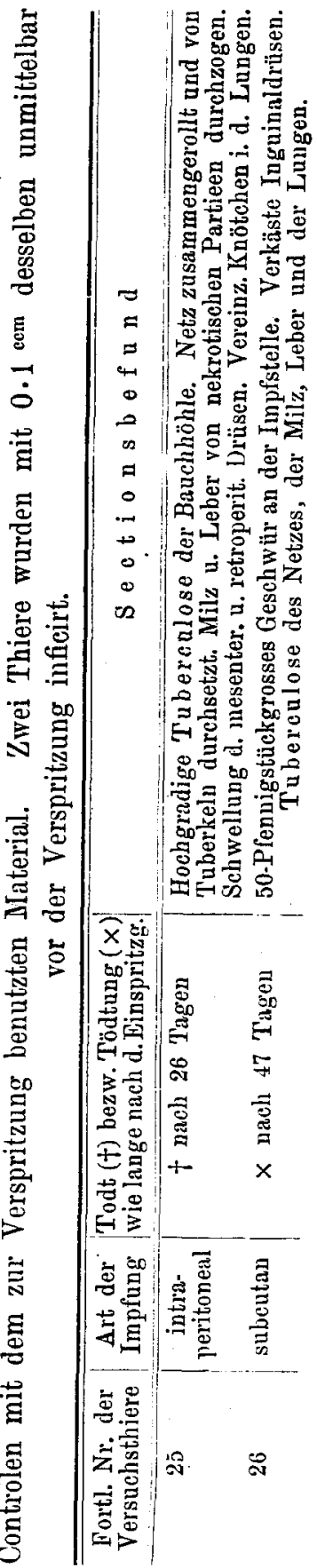

13 


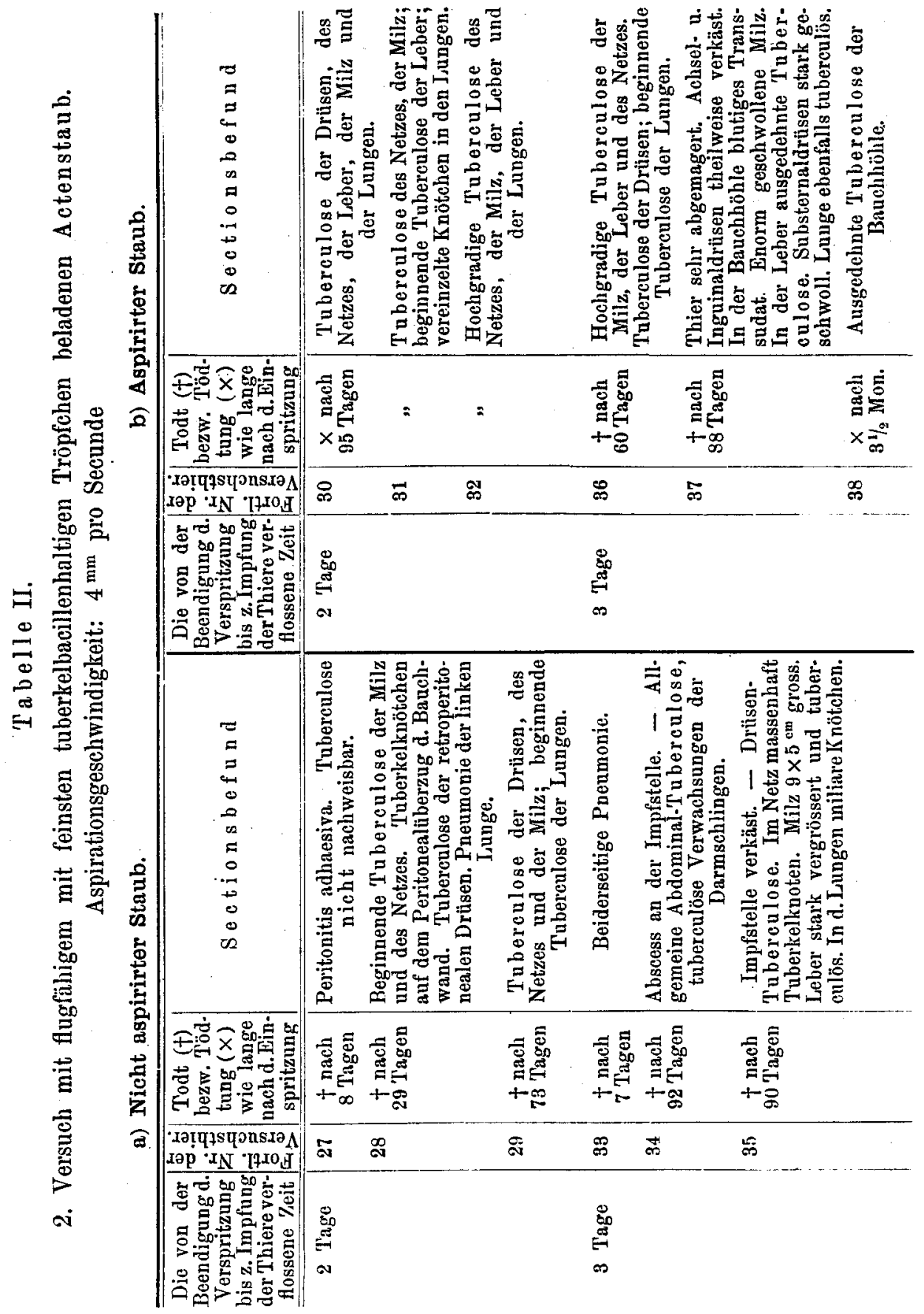




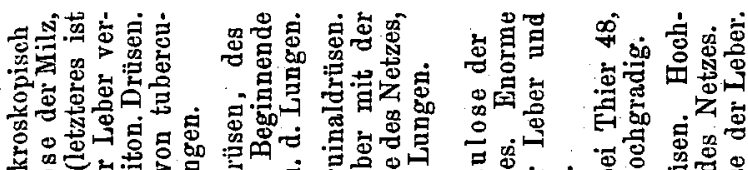

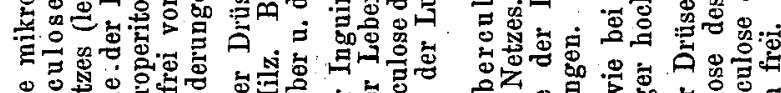

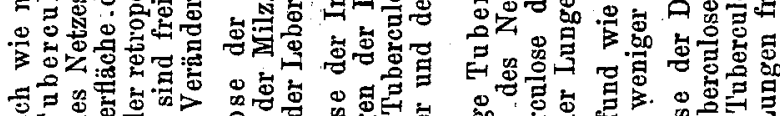

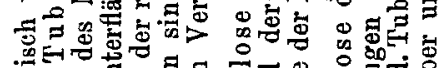

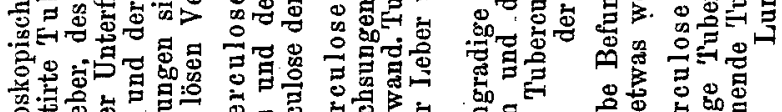

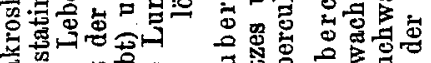

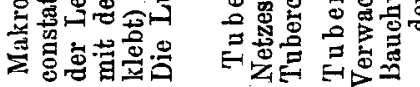

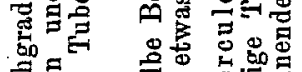

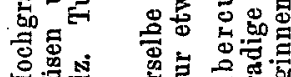

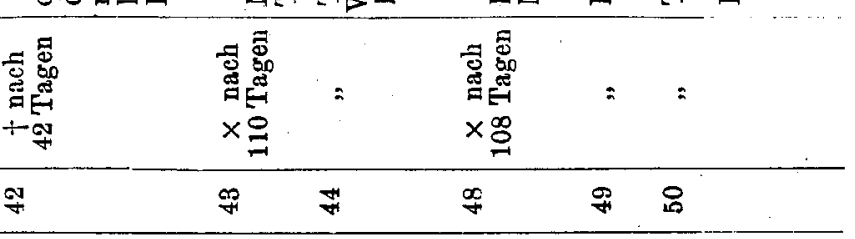

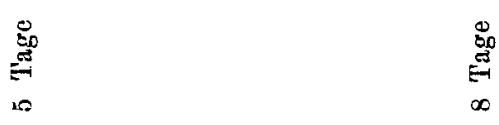

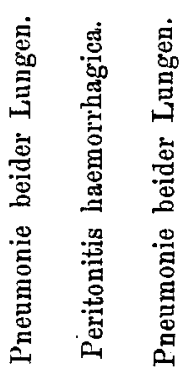

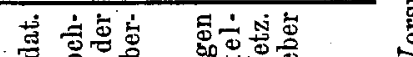

结苛

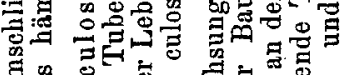

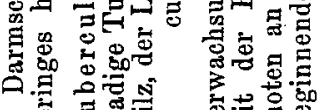

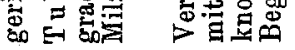

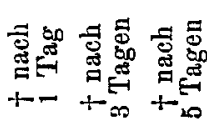

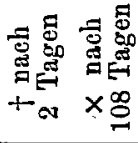

용 악 눈 윤

$\stackrel{8}{20}$ 
$4^{\mathrm{mm}}$ pro Secunde entsprach. Zu dem Zwecke wurde eine weitere Blechröhre von $12^{\mathrm{cm}}$ Durchmesser und ebenfalls $1^{\mathrm{m}}$ Länge gewählt. Ueber den Ausfall dieses Versuches giebt die Tabelle II nähere Aufschlüsse.

Die vorstehende Tabelle bringt zum Ausdruck, dass feinste, mit sehr geringen Strōmungen ( $4 \mathrm{~mm}$ pro Secunde) flugfähige Stäubchen, welche durch feinste Tröpfchen mit Tuberkelbacillen inficirt sind, letztere noch nach 8 Tagen in lebensfähigem Zustande weiterzuführen vermögen.

Um die Grenzen des Absterbens der Tuberkelbacillen unter den angegebenen Bedingungen näher bestimmen zu können, wurde am 6.II.03 ein dritter Verspritzungsversuch in die Wege geleitet.

Derselbe wurde in ganz analoger Weise wie der zweite angestellt.

Es sei hemerkt, dass durch Verspritzung eines verdünnten tuberculösen Sputums eine derartige Verteilung von Tuberkelbacillen erreicht wurde, dass durchschnittlich 1 Tuberkelbacillus auf 30 Gesichtsfelder kam. Als Untersuchungsintervalle warden 4, 8 und 14 Tage nach der Besprühung der staubbedeckten Objectträger gewählt. In der Parallelversuchsreihe wurde die Aspirationsgeschwindigkeit in der Neisser'schen Röhre auf $3^{\mathrm{mm}}$ pro Secunde bemessen.

Das Ergebniss dieses Versuehes spiegelt sich in der folgenden Tabelle III wieder.

- Es zeigt sich also, dass erst nach 14 Tagen die Tuberkelbacillen sowohl in der abgelagerten Staubmasse wie in dessen feinstem dureh geringste Luftströme flugfähigen Antheil abgestorben waren; nach 8 Tagen wurden in beiden Fällen noch lebensfähige Tuberkelbacillen angetroffen.

In meiner oben citirten Arbeit ist angegeben, dass die mit feinsten Tröpfchen verspritzten Tuberkelbacillen durchschnittlich 5 Tage nach der Verspritzung abgestorben seien.

Die drei neuerdings angestellten Versuche haben jedoch ergeben, dass die Grenze des Absterbens doch noch weiter hinauszurücken ist, dass also ein Absterben häufig erst 8 bis 14 Tage nach der Verspritzung erfolgt.

Wie erklären sich nun die etwas divergirenden . Resultate?

Nach Ausweis der mikroskopischen Präpurate dürfte in der Tröpfchengrösse und transportierten Bazillenmenge der Grund nicht za suchen sein. Beide Male glaube ich die feinsten überhaupt zu gewinnenden Tröpfchen erzielt zu haben, wenn auch auf verschiedene Weise.

Die etwas abweichenden Resultate dürften vielmehr in Folgendem begründet sein:

Einmal sind die beiden früheren Versuche in Monaten mit längerer Tagesdauer - October und März -, diese jedoch im Dezember, Januar und Februar angestellt. 


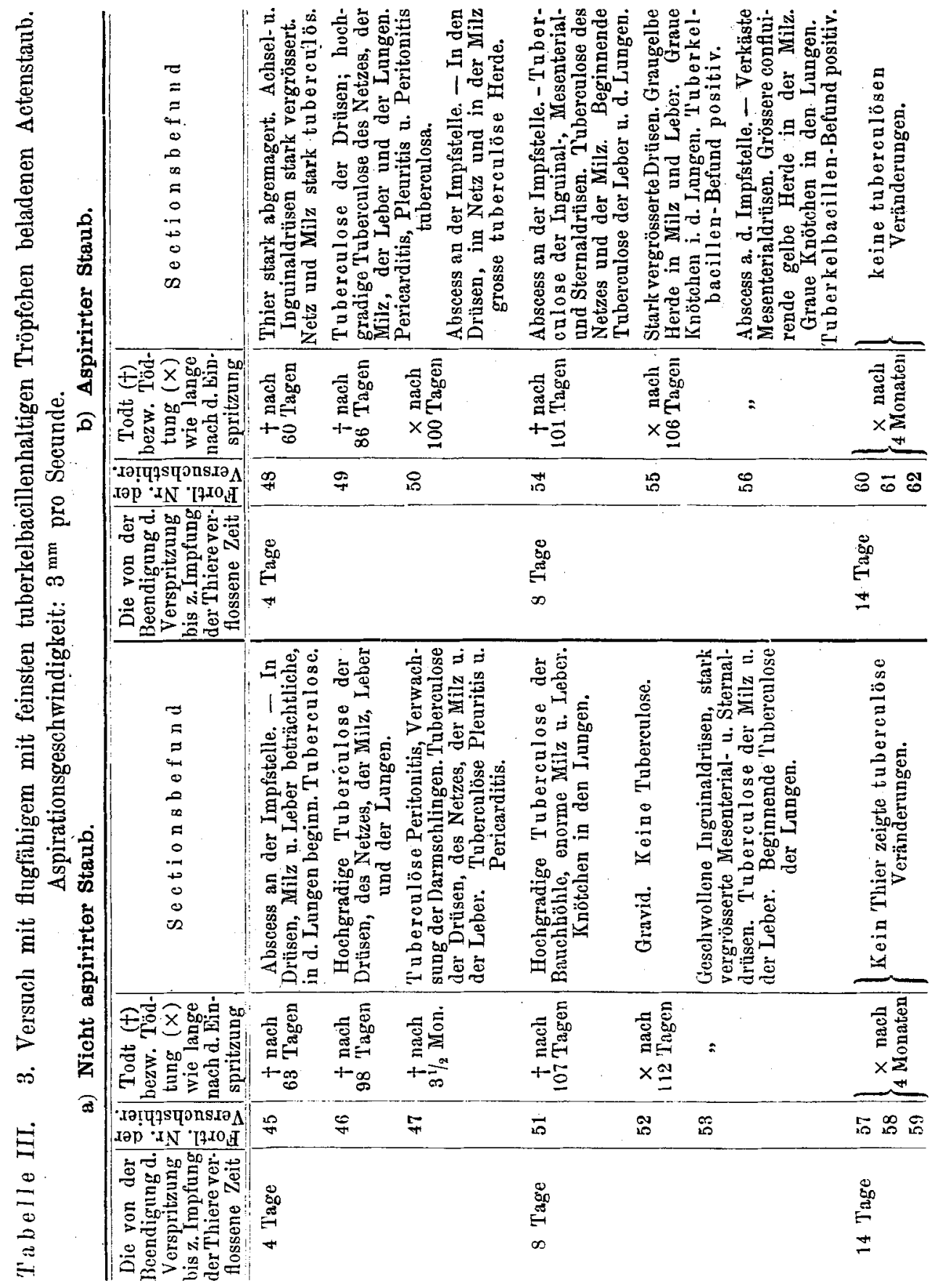


Zum andern wurden damals die bacillentragenden Tröpfchen auf Glas, diesmal anf Staub aufgefangen. Gerade auf letzteren dürften nun manche Bacillen so gefallen sein, dass sie einen grösseren Schutz gegen die Wirkung des diffusen Tageslichtes hatten.

Endlich ist noch zu erwähnen, dass in den beiden ersten Versuchen die 2 den Ausschlag gebenden Meerschweinchen aus äusseren Gründen schon 50 bezw. 60 Tage nach der Infection getötet wurden, während in diesem Versuche eine Tötung erst 3 bis 4 Monate nach der Infection erfolgte.

In einer Verschiedenheit der Tuberkerbacillenstämme dürfte der Grund für die Verschiedenheit der erbaltenen Resultate nicht zu suchen sein, da die letzten drei Versuche übereinstimmend ausfielen, obwohl jedes Mal ein Sputum anderer Herkunft gewählt wurde.

Jedenfalls dürfte jetzt daran festzuhalten sein, dass die mit feinsten Tröpfchen verspritzten Tuberkelbacillen im diffusen Tageslicht im allgemeinen erst nach 8 bis 14 Tagen absterben, eine Dauer der Lebensfähigkeit, welche ron keinem bekannten Krankheitserreger (abgesehen von gewissen pathogenen Kokken und Bacteriensporen) auch nicht annähernd erreicht wird (vgl. Tabelle XVI meiner oben citirten Arbeit).

Diese Thatsache lässt die Bedeutung der Tröpfcheninfection für die Ausbreitung der Tuberculose noch erheblicher erscheinen, als man bisher annahm.

Die zweite Kategorie der Versuche hatte die Beantwortung der Frage nach der Lebensdauer der in feinsten Sputumstäubchen eingeschlossenen Tuberkelbacillen zum Gegenstand.

Die Gewinnung feinsten tuberculösen Sputumstaubes hatte naturgemäss einige Schwierigkeit und wurde in folgender Weise erzielt:

Feiner steriler Quarzkies wurde auf einer etwa $40^{\mathrm{cm}}$ langen und $20 \mathrm{~cm}$ breiten Glasplatte in einer etwa $1 / 2 \mathrm{~cm}$ hohen Schicht aufgetragen. Auf derselben wurden ca. $200 \mathrm{~cm}$ tuberkelbacillenhaltigen Sputum's (Gaffky's Tabelle Nr. IX) in ziemlich dicker Schicht ausgebreitet. Letzteres haftete nach achttägiger Auf bewahrung bei Zimmertemperatur dem Quarzsand fest an. Nun wurde die ganze Masse mit einem Messer vorsichtig von der Glasplatte gelöst, was ziemlich leicht und ohne sichtbare Staubentwickelung gelang.

Darauf wurde die Mlasse in eine Literflasche, in welcher durch Schütteln Sputumstäubchen sich bilden sollten, gebracht und noch 2 Tage in einem Brutschrank bei $30^{\circ} \mathrm{C}$. auf bewahrt. In letzterem waren zwecks energischer Trocknung eine Reihe ron Schalen mit Chlorcalcium ausgestellt. 
Die Gewinnung und das Auffangen des feinsten Sputumstaubes wird durch die beigegebene Fig. 2 erläutert. Die die angetrocknete Sputummasse enthaltende Zerstäubungsflasche $\boldsymbol{b}$ ist mit einem Kautschukgebläse $a$ und mit einer Glasglocke $c$ verbunden, unter welcher sich wieder eine Reibe von Objectträgern zum Auffangen der Stäubchen befinden.

Trotz kräftigen. Schüttelns löste sich bei den ersten Stössen nichts von dem angetrockneten Material los. Erst allmählich entstand bei weiterem energischen Schütteln ein ganz feiner weisslicher Staub, und zwar jetzt in ziemlichen Mengen. Derselbe wurde mit Hülfe des Doppelgebläses $\boldsymbol{a}$ in die Glasglocke $c$ übergetrieben und setzte sich zum grössten Theil auf den am Boden derselben befindlichen 13 Objectträgern ab. Die entweichende tuberkelbacillenhaltige Stäubchen führende Luft musste zunächst eine im Glühen erhaltene Kupferspirale $\boldsymbol{d}$ passiren und wurde dann in einen durch eine Lockflamme erwärmten Abzugskanal geführt.

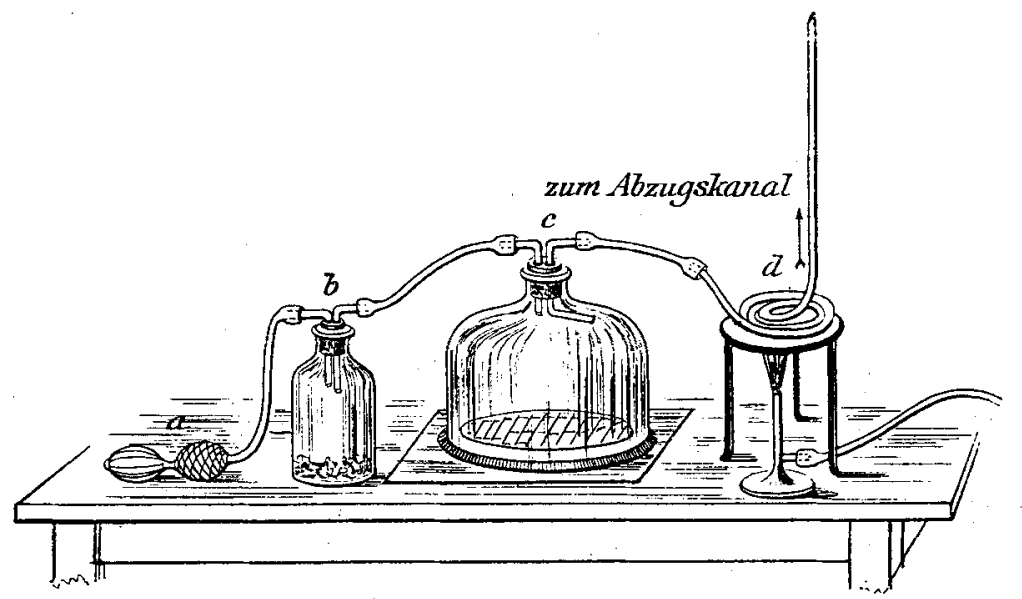

Fig. 2. Apparat zur Gewinnung feinen Sputumstaubes.

$a$ Doppelgebläse, $b$ Zerstäubungsflasche, $c$ Glasglocke zum Auffangen des gewonnenen Staubes, $d$ Kupferspirale.

Auf die geschilderte Weise waren nach verhältnissmässig kurzer Zeit die exponirten Objectträger mit einer dichten Lage gelblichweissen Sputumstaubes bedeckt.

Im ganzen wurden so am 14. II. 034 mal 13 objecttrăger mit tuberkulösem Sputumstaub beschickt. Dieselben wurden analog den ersten Versuchen in dem Glaskasten dem diffusen Tageslichte ausgesetzt. Directe Besonnung war ferngehalten. Es sei generell hier bemerkt, dass bezüglich der Belichtung in allen folgenden Versuchen dieselben Bedingungen vorlagen. 
Die mit dem Sputumstaub hergestellten Deckglaspräparate zeigten wohlerhaltene Tuberkelbacillen, die z. T. einzeln lagen, häufiger jedoch zu kleinen Häufchen von 4 bis 10 Bacillen zusammengelagert waren.

Ausserdem sah man Kokkenhäufchen, nicht mehr scharf umschriebene Zellkerne und kleinste Quarzpartikel in den Präparaten.

Unmittelbar nach Beendigung der Zerstäubungen wurden drei Meerschweinchen mit dem Sputumstaub von drei Objectträgern intraperitoneal infizirt.

In Intervallen von 2, 6, 12 und 25 Tagen wurden die weiteren Prüfungen auf die Lebensdauer der Tuberkelbacillen in den gewonnenen Stäubchen in der für die Versuche der ersten Categorie bereits beschriebenen Weise ausgeführt. Zum Transport der Stäubchen wurde in diesen wie in allen folgenden Versuchen die Geschwindigkeit eines Luftstroms von 3 bis $4^{\mathrm{mm}}$ in der Neisser'schen Röhre innegehalten.

Das Ergebniss des Versuchs gibt die folgende Tabelle IV wieder.

Die 'Tabelle zeigt also, dass nur die Controltiere tuberculös wurden, dass jedoch die Tuberkelbacillen in den nur 2 Tage gelagerten Stäubchen bereits abgestorben waren.

Dieser auffallende Befund dürfte wohl darin zu suchen sein, dass eine relativ lange Zeit zum Trocknen der Sputummasse verwendet, ferner auch darin, dass bei dem energischen Schütteln mit dem Quarzsand auch ein Theil der Tuberkelbacillen mechaniseb zertrümmert wurde. Bei einer Wiederholung des Versuches am 21. III. 03 wurden diese beiden Punkte berücksichtigt.

Die Dauer des Antrocknens des tuberkelbacillenreichen Sputums an den Quarzsand wurde auf 3 Tage beschränkt, und es wurde zur Zerstäubung des Materials sofort nach dem Einfüllen in die Flasche geschritten. Das zur Zerstäubung dienende Material wurde in $\mathrm{zwei}$ Portionen geteilt, um ein zu langes und intensives Schütteln zu vermeiden. Im Ganzen wurden wieder 4 Scheiben zu je 13 Objectträgern mit Sputumstaub besät.

Als Untersuchungstermine wurden 4, 7, 10 und 20 Tage nach der Zerstāubung gewählt.

In der folgenden Tabelle $\mathrm{V}$ ist das Resultat dieses Versuches niedergelegt.

Es geht aus derselben hervor, dass zwischen dem 4. und 7. Tage nach der Zerstäubung das Absterben der in den flugfähigen Stäubchen enthaltenen Tuberkelbacillen erfolgte, immerhin eine geringere Lebensdauer als für die mit feinsten Tröpfchen verspritzten Tuberkelbazillen festgestellt wurde. Ueberblickt man die beiden mit angetrockneten Sputummassen angestellten Versuche, so ist hervorzuheben einmal die 


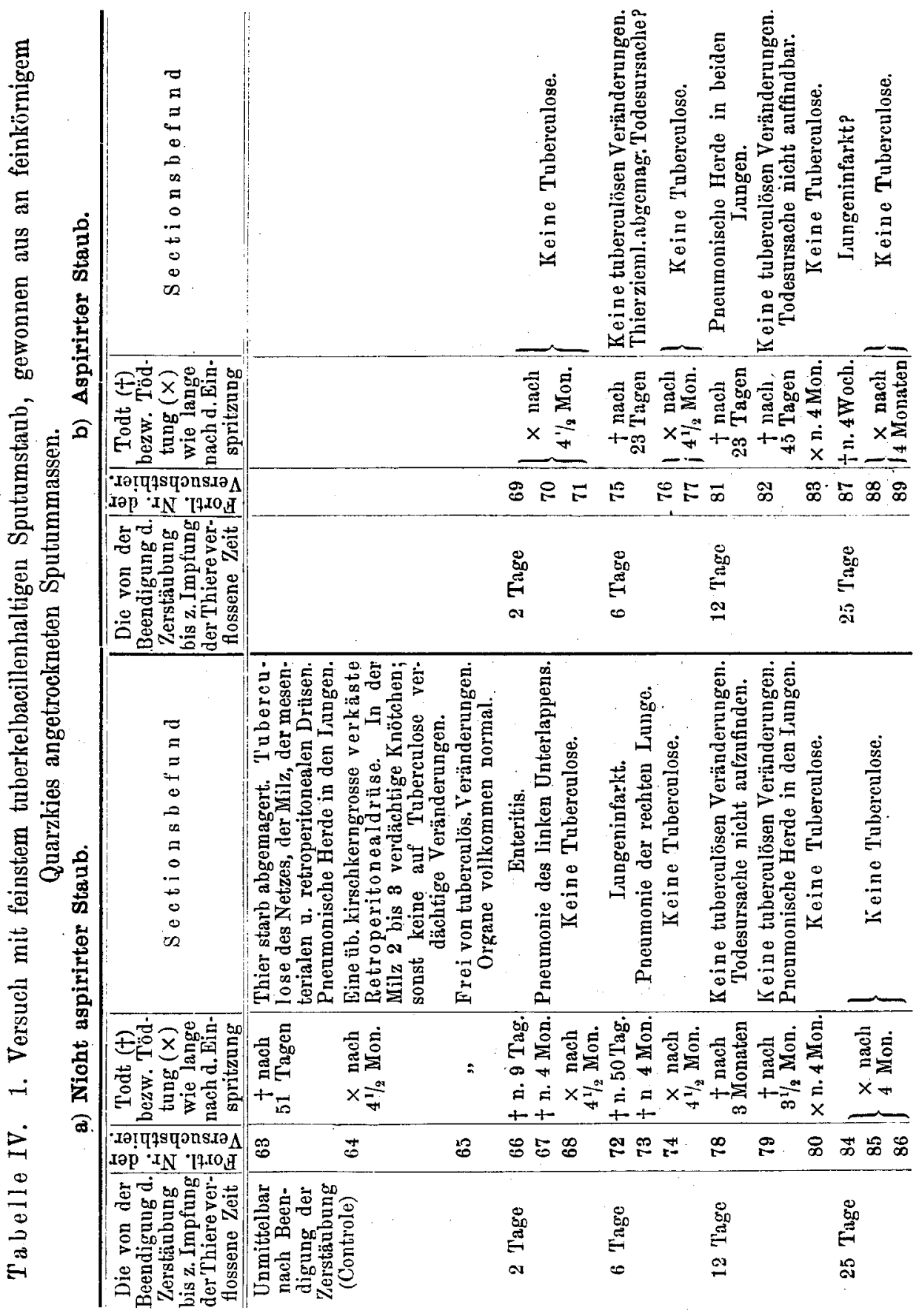




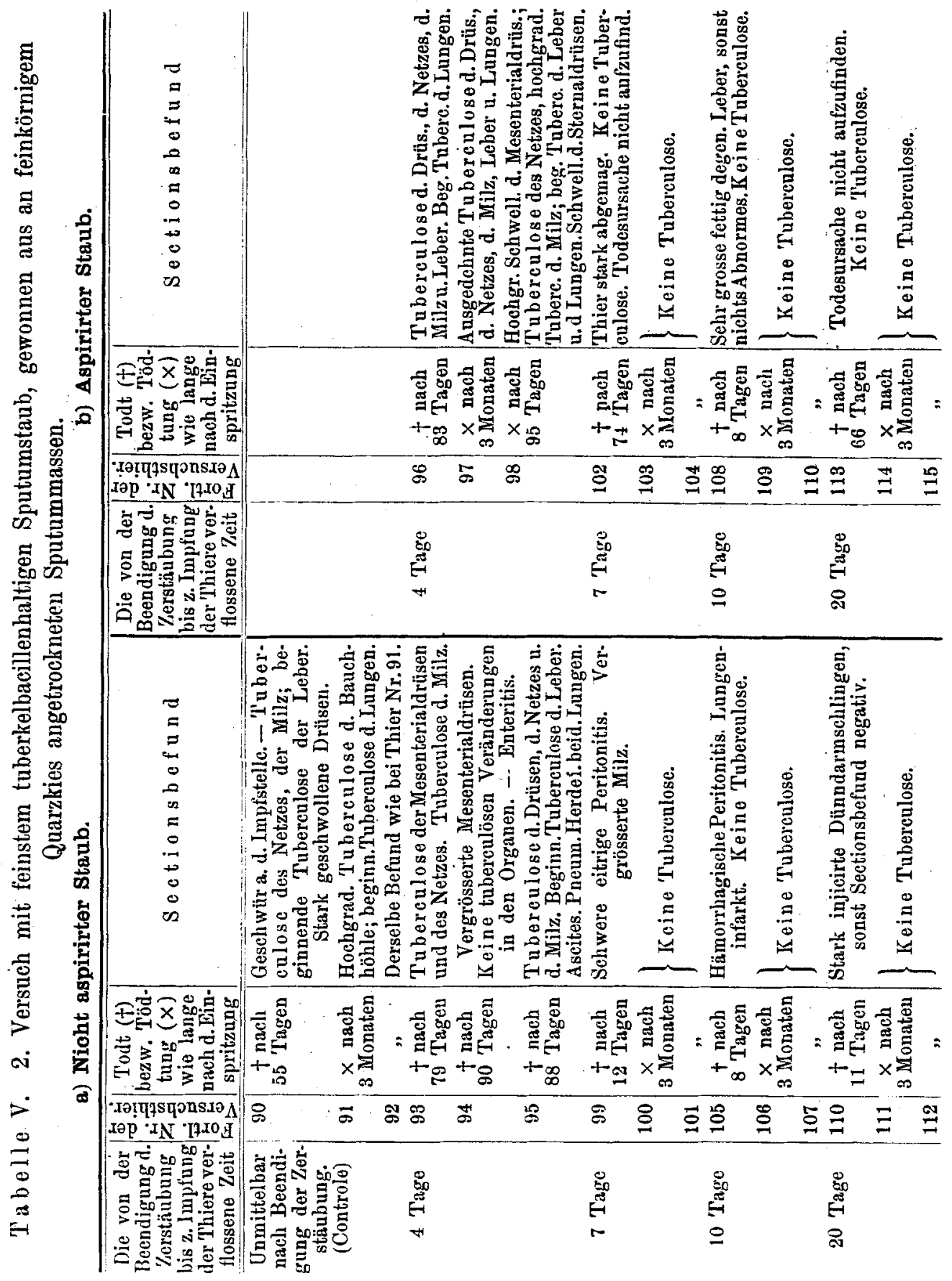


ziemliche Schwierigkeit der Gewinnung feinster Sputumstäubchen überhaupt, zum andern die relativ kurze Lebensdauer der in den Sputumstäubchen enthaltenen Tuberkelbacillen, die in dem einen Versuche nicht einmal 2 Tage, in dem zweiten nur 4 Tage betrug.

Für die Beurtheilung der praktischen Verhältnisse dürften die gewonnenen Ergebnisse wohl verwerthet werden können. Bei der bekannten hygroskopisehen Eigenschaft tuberculösen Sputums dürfte es überhaupt nur unter besonderen Bedingungen zur Bildung feinster flugfähiger Stäubchen kommen. Derartige den angeführten Versuchen entsprechende Bedingungen dürften z. B. in solehen Räumen vorliegen, wo der Fussboden, wie in manchen ländlichen Bezirken üblich, mit Sand bestreut wird. Hier wird es gelegentlich zu einer intensiven zur Bildung feinster Stäubchen nothwendigen Zerreibung des Sputums kommen. Im Allgemeinen werden jedoch die zur Bildung flugfähiger lebende Tuberkelbacillen führenden Sputumstäubchen nothwendigen Umstände so selten zusammentreffen, dass die dadurch bedingten Infectionschancen als nicht erhebliche anzusehen sein dürften.

Wie bereits Heymann ${ }^{1}$ zeigte, ist die Qnalität des tuberculösen Staubes hinsichtlich der grösseren oder geringeren Infectionschancen von nicht zu unterschätzender Bedeutung. Es liess sich nachweisen, dass die Loslösung feinster bakterienhaltiger Stäubchen und die Schwebedauer derselben von dem jerreiligen Vehikel der Bakterien abhängig ist. Eine besonders lange Schwebedauer von 30 bis 60 Minuten zeigten Taschentuchfäserchen, während der von Teppichen und Dielen herrührende Sputumstaub sich bald nach dem Abreiben wieder niedersetzte. Es ist leicht verständlich, dass gerade die Stäubchen ersterer Kategorie am ehesten zu Luftinfectionen Anlass geben können.

$\mathrm{Zu}$ meinen in dieser Richtung angestellten Versuchen wählte ich stark wollige, leicht fasernde Proben von Kleiderstoffen, an denen das aufgetragene Sputum leicht antrocknete und wo die Loslösung vom Fäserchen unschwer gelang.

Ferner ist auch das praktische Interesse an den Stäubchen dieser Provenienz nicht gering, da bekanntlich viele namentlich unreinliche Phthisiker Sputumreste an den Kleidern abzuwischen pflegen. Der erste derartige Versuch wurde in folgender Weise vorbereitet:

Auf 8 ca. 100 qom grossen trocken sterilisirten wolligen Kleiderstofflappen wurde tuberculöses Sputum (Gaffky's Tabelle Nr. IX) mit einem

1 A. a. 0 . 
Spatel in dünner Schicht ausgestrichen. Nachdem dasselbe während 8 Tage bei Zimmertemperatur, vor Licht geschützt, angetrocknet war, wurdén die einzelnen Lappen in ca. $\mathbf{3}^{\mathrm{cm}}$ breite Streifen geschnitten.

Die eine Hälfte derselben kam alsdann in einen Kautschukbeutel von $18 \mathrm{em}$ Länge und $15^{\mathrm{cm}}$ Breite, welcher mit einem doppelt durchbohrten Gummistöpsel rerschlossen war. Der Kautschukbeutel wurde an Stelle der bei der vorigen Versuchskategorie benutzten Zerstäubungsflasche in die im Uebrigen gleiche Versuchsanordnung eingeschaltet. Der Kautschukbeutel und mit ihm sein Inhalt wurde nun etwa eine Stunde lang gerieben und gezerrt. Von Zeit zu Zeit wurde mit dem Doppelgebläse Luft durch den Beutel getrieben, um die losgelösten Fäserchen in die Glasglocke zu jagen.

Nach der angegebenen Zeit waren die exponirten Objectträger ziemlich reichlich mit feinen Kleiderfasern bedeckt.

Nach Ablauf von 3 Stunden nach Beendigung dieser Manipulation (es wurde mit Rücksicht auf das Absitzen der Stäubchen so lange gewartet) wurde die andere Hälfte·der sputumbeschmutzten Kleiderstreifen in derselben Weise behandelt und so noch eine weitere Serie von Objectträgern mit Kleiderfäserchen beschickt.

Die Scheiben mit den damit beladenen Objectträgern wurden wieder in den oben beschriebenen Glaskasten dem diffusen Tageslicht ausgesetzt. Auf den zur Controle exponirten Deckgläschen wurden an manchen Fäserchen Tuberkelbacillen mikroskopisch nachgewiesen. Als Termine für die Prüfung auf die Lebensdauer der an den Fäserchen haftenden Tuberkelbacillen wurden 7, 17 und 30 Tage nach der Zerstäubung, welche am 23. II. 03 stattfand, ausersehen.

Die folgende Tabelle VI giebt das Resultat dieses Versuches wieder.

Nach Ausweis der nachstehenden Tabelle waren wohl kurz nach Beendigung der Zerstäubung die Faserstäubchen noch mit lebenden Tuberkelbacillen behaftet, jedoch waren dieselben in dem 7 Tage lang gelagerten Faserstaub nicht mehr infectionstüchtig.

Dieses wider Erwarten rasche Absterben der Tuberkelbacillen an den Kleiderfäserchen war möglicherweise in der vorausgegangenen relativ langen Antrocknungszeit (8 Tage) des tuberculösen Sputums an den Stoffstücken begründet.

In einem zweiten Versuche Ende März 1903 wurden wiederum 8 $100^{\mathrm{gcm}}$ grosse Tuchstücke mit tuberculösem Sputum (Gaffky's Tabelle Nr. IX) und zwar in sehr dünner Schicht bestrichen.

Nach 24 Stunden war das Material bereits so fest angetrocknet, dass zur weiteren Verarbeitung in der oben dargestellten Weise geschritten werden konnte. Als Untersuchungstermine wurden 5, 10 und 20 Tage nach der Zerstäubung gewählt. 
Dauer der Lebensfähigkeit von TUberkelbacillen.

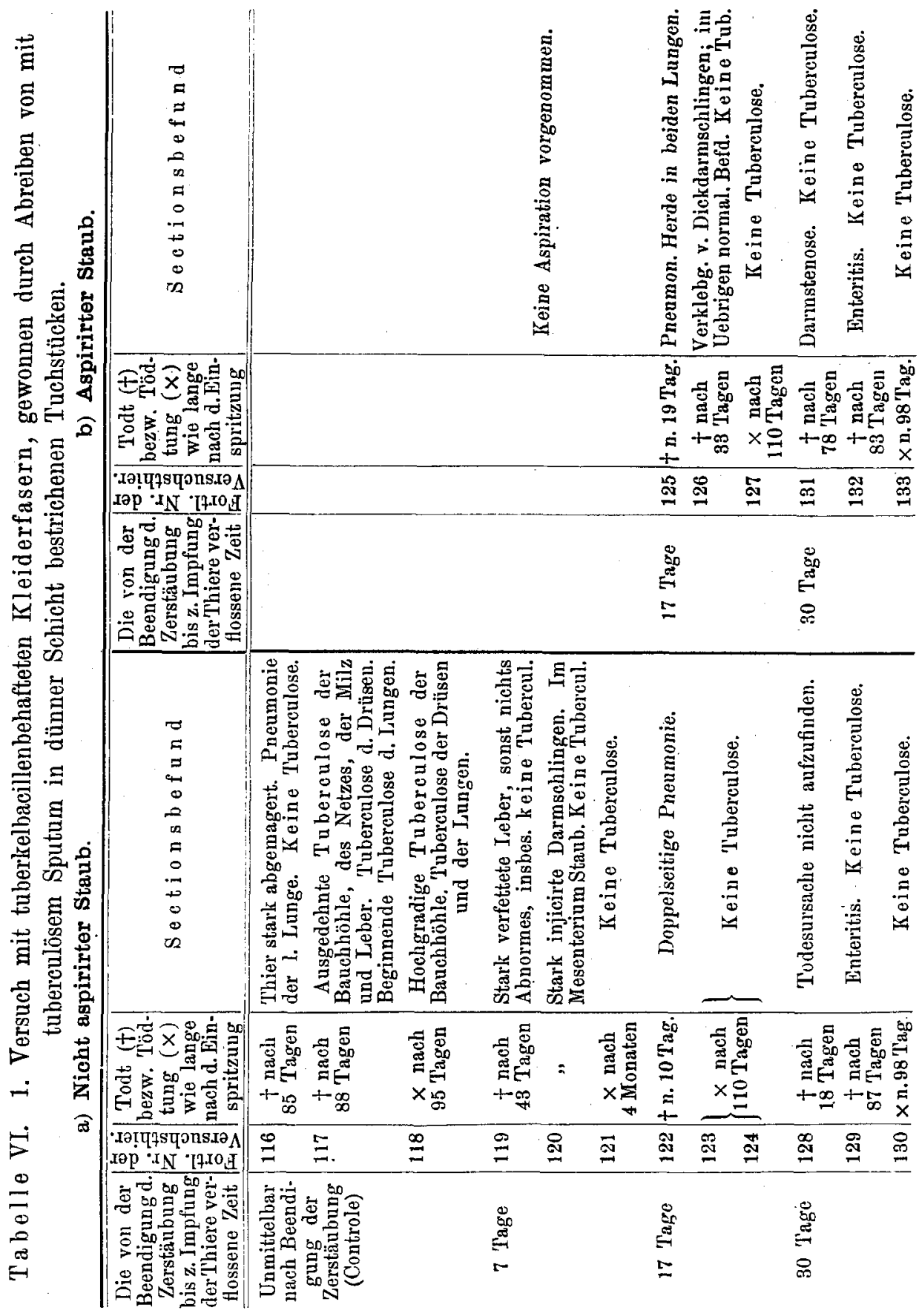




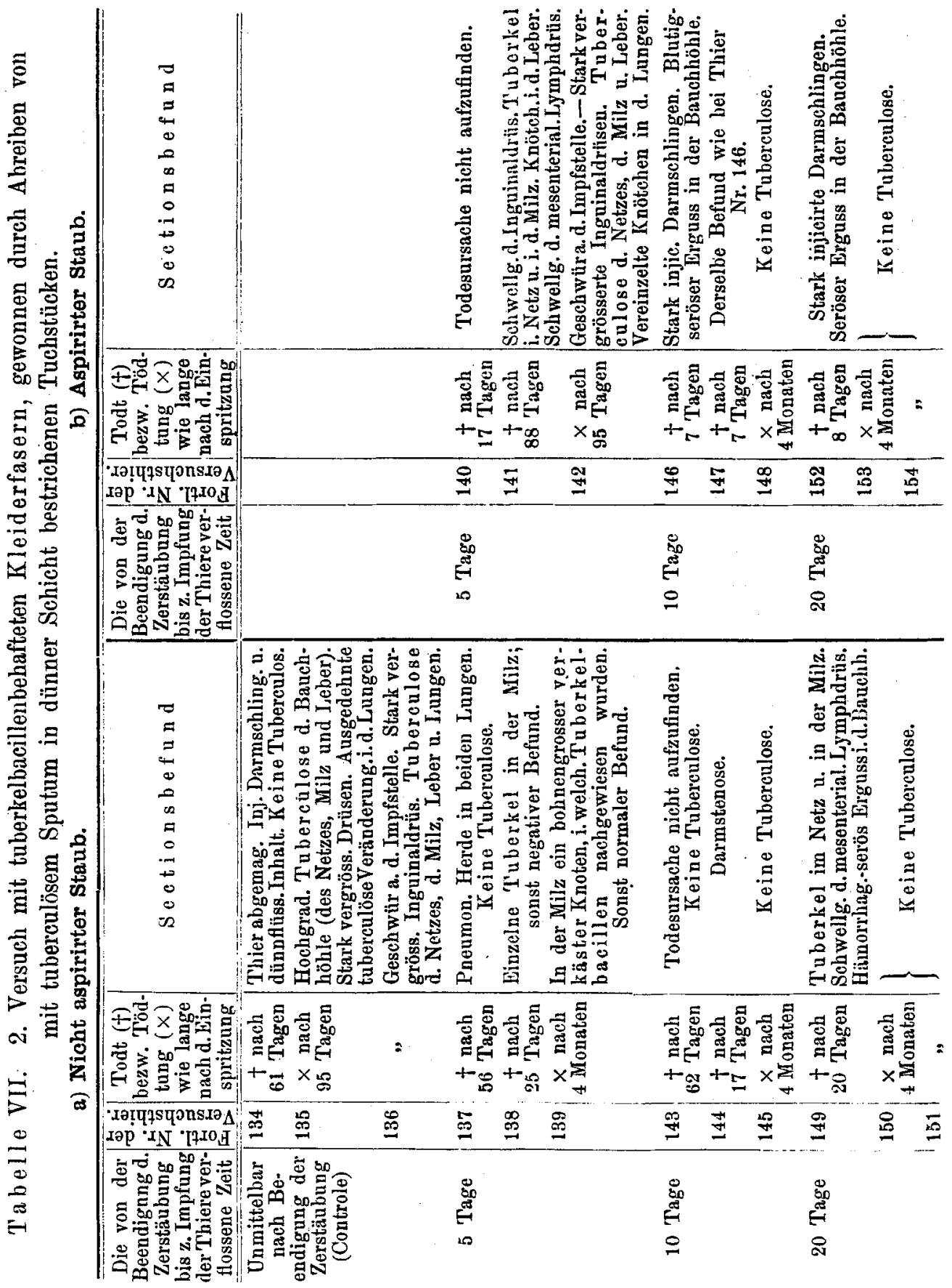


Der Ablauf des Versuches erhellt aus der Tabelle VII.

Dieselbe zeigt also, dass . tuberkelbacillenbehaftete flugfähige Kleiderfasern, welche kurz nach dem Antrocknen tuberculösen Sputums an Kleiderstoffe sich losgelöst haben, nach 5 Tagen noch Infection en verursachen können; am 10. Tage nach der Loslösung wurden diese feinsten flugfähigen Fäserchen nicht mehr infectionsfähig gefunden.

Dass gröbere, mit grösseren Sputumtheilen behaftete, jedoch nicht flugfähige Stofffasern und Sputumpartikel selbst gelegentlich noch nach längerer Zeit - in unserem Versuche noch nach 20 Tagen - lebensfähige Tuberkelbacillen führen können, erscheint nach dem schon früher von mir aufgestellten Satze nicht auffallend, wonach die Lebensdauer der Bakterien direct abhängig ist von der Dichtigkeit der den schädlichen Einflüssen des Lichts und der Austrocknung ausgesetzten Bakterienmassen.

In einer letzten Versuchsreihe wurde als Vehikel der Tuberkelbacillen feinster Strassenstaub, der ja ebenfalls häufig mit tuberculösem Sputum vermischt ist, gewählt.

Der Versuch gestaltete sich in folgender Weise:

Gewöhnlicher feiner Strassenstaub wurde durch einen Siebsatz geschickt, und das feinste so gewonnene Material wurde in grossen Schalen in nicht zu dichten Lagen mehrere Stunden lang bei $160^{\circ} \mathrm{C}$. im Trockenschrank sterilisirt.

Alsdann wurde das Staubmaterial $\mathrm{zu}$ etwa gleichen Theilen mit tuberkelbacillenreichem Sputum (Gaffky's Tabelle Nr. IX) in flachen Glasschalen in etwa $1^{\mathrm{cm}}$ hoher Schicht durch Umrühren innig rermischt.

Die so beschickten Schalen wurden darauf bei $28^{\circ} \mathrm{C}$. im Dunkeln aufbewahrt. Nach 2 Tagen war das Material so trocken, dass es von den Schalen losgelöst und zur Zerstäubung benutzt werden konnte. Um eine Ausstreuung von tuberkelbacillenhaltigem Staube zu vermeiden, wurde die Loslösung des Materials in einem besonderen Kasten vorgenommen.

Der betreffende, mit Glasscheiben versehene, luftlicht abschliessbare Kasten war gerade so gross, dass in ihm die Loslösung des Materials von den Schalen und das Einfüllen desselben in die Zerstäubungsflasche von 1 Liter Inhalt stattfinden konnte. Das Manipuliren in dem Kasten war dadurch ermöglicht, dass in zwei gegenüberliegenden Seitenwänden runde mit Gummimanschetten versehene Oeffnungen angebracht waren, durch welche die Hände hindurchgesteckt werden konnten. Die Gummimanschetten umsehlossen alsdann fest die Handgelenke, so dass kein Staub entweichen konnte. 
Eine halbe Stunde nach Einfüllen des Materials in die Flasche wurden die Hände rorsichtig aus den Stulpen herausgezogen und desinficirt. Alsdann wurde auch die Flasche mit dem zu zerstäubenden Material aus dem Kasten entfernt und ihre Oberfläehe mit 5\% iger Sublimatlösung abgerieben.

Die Zerstäubungsflasche wurde nun in der bei der 2. und 3. Versuchskategorie geschilderten. Weise mit der eine Reihe von Objectträgern bergenden Glasglocke verbunden.

Durch kräftiges Schütteln des Inhalts der Flasche gelang ohne besondere Schwierigkeit die Zerlegung desselben in dichte Staubwolken, welche durch ein Doppelgebläse in die Glasglocke übergetrieben wurden.

Auf diese Weise wurden die exponirten Objectträger in kurzer Zeit mit einer zusammenhängenden Schicht feinen Staubes bedeckt.

Im Ganzen wurden vier Zerstäubungen und zwar je zwei am 30. und 31. III. 03 auf die beschriebene Weise vorgenommen. - In den mit dem niedergefallenen Staube angefertigten Deckglaspräparaten wurden an einigen Staubpartikeln eine oder einige wenige Tuberkelbacillen beobachtet.

Als Prüfungstermine auf die Dauer der Lebensfähigkeit der an feinsten Strassenstäubchen haftenden Tuberkelbaeillen wurden 3, 8, 15 und 25 Tage nach der Zerstäubung gewählt.

Die folgende Tabelle VIII bringt den Verlauf des Versuches zum Ausdruck.

Diese Tabelle lehrt, dass feine Strassenstäubchen wenigstens 8 Tage lang lebensfähige Tuberkelbacillen beherbergen können, dass aber an ibrem feinsten flugfähigen Antheil Tuberkelbacillen wohl noch nach 3 Tagen, aber nicht mehr nach 8 Tagen nachgewiesen werden konnten. Die Dauer der Lebensfähigkeit derartiger flugfähiger Stäubchen ist demnach eine eng bemessene. Wobl gemerkt, gelten diese Befunde nur für diffuses Tageslicht.

Steinitz ${ }^{1}$ hatte bereits auf Grund seiner Versuche in dem gasförmig verwendeten Formalin ein wirksames Desinfectionsmittel für angetrocknete Sputummassen, sofern es sich nicht um allzu dicke Schichten handelte, constatirt. Zweifellos sind trockene Staubschichten, welche Tuberkelbacillen enthalten, viel leichter vom Formaldehydgas zu durchdringen, als solche in continuo angetrockneten Sputa; und die Verhältnisse von Concentration und Zeitdauer, welche Steinitz in seinen Versuchen wirksam fand, werden erst recht für Sputumstaub Geltung haben.

'Steinitz, Diese Zeitschrift. 1901. Bd.XXXVII. 
DaUer der Lebensfähigkeit von Tuberkelbadilen.

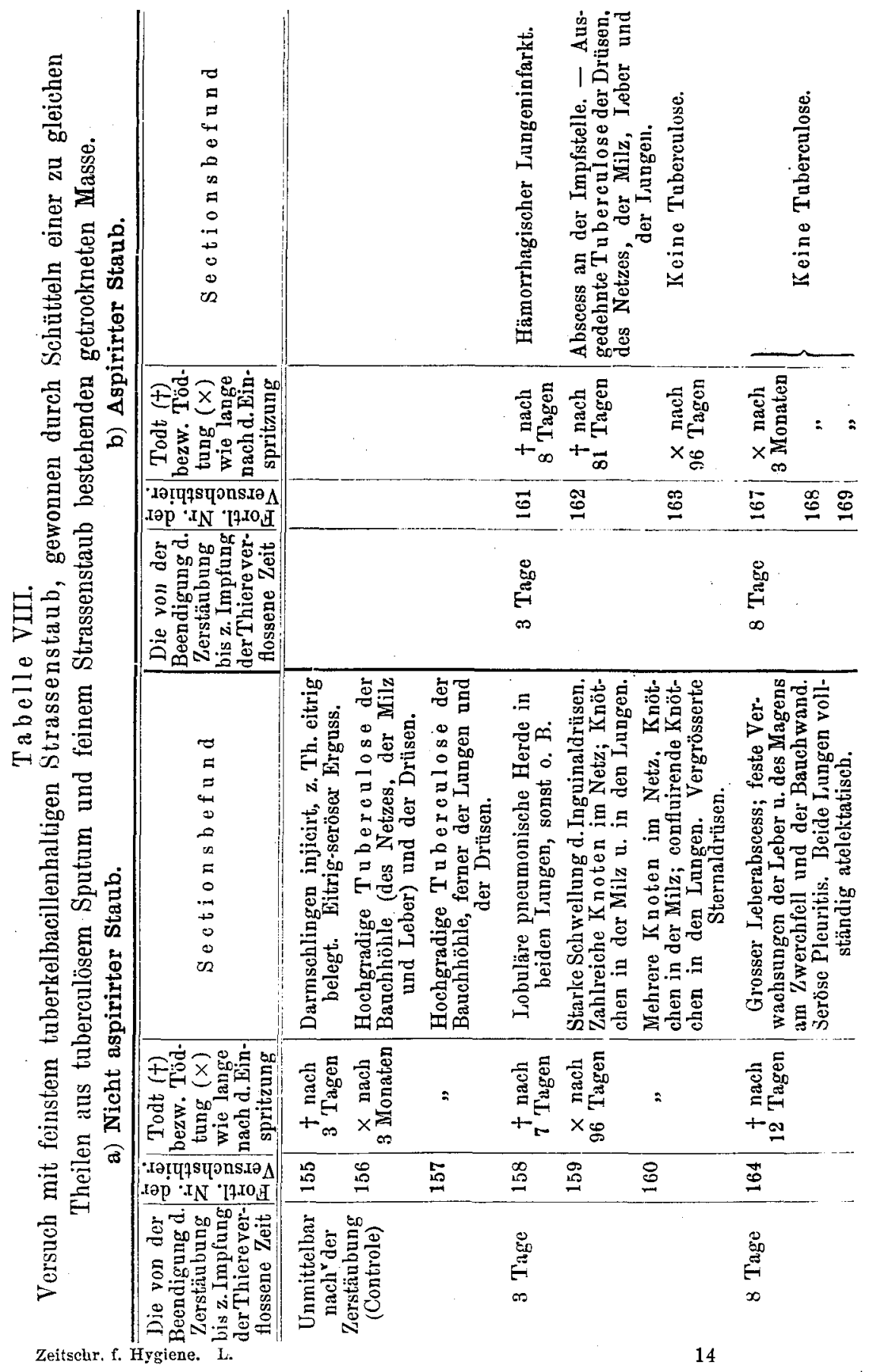




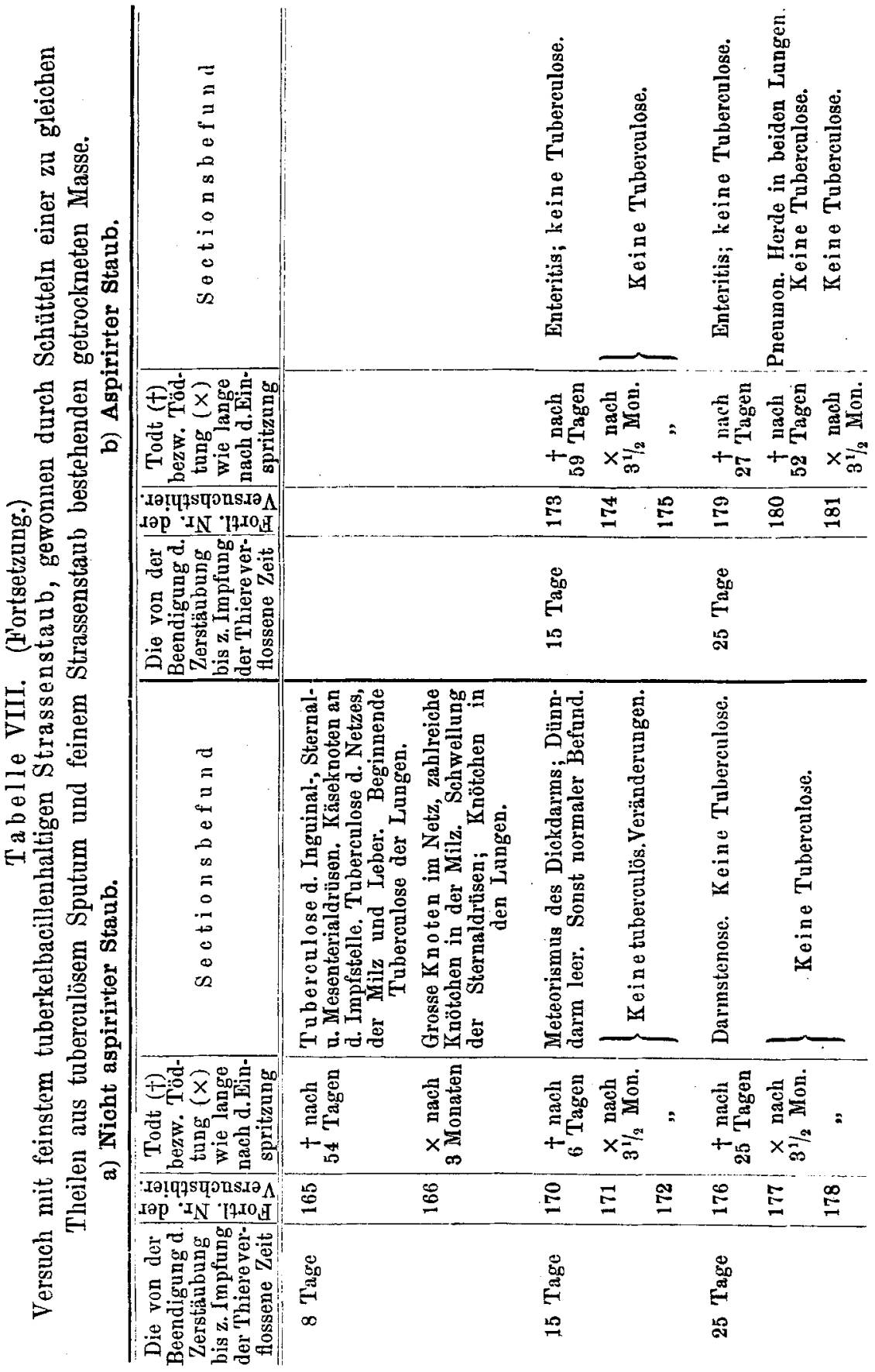


Nun hat allerdings Steinitz auf Grund seiner Versuche verlangt, die Einwirkungsdauer zu verlängern, damit die angetrockneten Sputa gehörig aufweichen und dadurch dem Formaldehyd zugāngig werden können. In Folge dessen ist in den meisten Desinfectionsordnungen die Bestimmung aufgenommen worden, dass in Fällen von Tuberculose stets $5 \mathrm{grm}$ Formaldehyd pro Cubikcentimeter 7 Stunden einwirken müssen.

Gerade die längere Zeitdauer wird aber in praxi oft lästig empfunden. Mir lag daher daran, festzustellen, ob der Sputumstaub sich nicht in kürzerer Zeit, wenn auch mit grösseren Formaldehydmengen desinficieren liesse. Dies würde einen praktischen $\nabla$ ortheil bedeuten, insofern die groben angetrockneten Sputummassen in einer Wohnung doch stets leicht erkannt und mit Sublimatlösung desinficirt werden.

$\mathrm{Zu}$ den unter diesem Gesichtspunkt Anfangs April 1903 ausgeführten beiden Versuchen wurde sehr tuberkelbacillenreiches Sputum auf Quarzkies innerhalb 3 Tagen angetrocknet, darauf zerstäubt und auf Objectträgern aufgefangen.

Die Formalindesinfection wurde unmittelbar nach dem Absitzen der Stäubchen vorgenommen, nachdem vorher zur Controle 4 Objectträger mit $15^{\mathrm{cem}}$ Nährbrühe abgeschwemmt und die Schwemmflüssigkeit auf 3 Meerschweinchen intraperitoneal verimpft worden war. Die übrigen Objectträger wurden in einem Raume von $15^{\mathrm{cbm}}$, entfernt von dem aufgestellten Breslauer Apparate, der Formalindesinfection mit $3 \frac{1}{2}$ stündiger Desinfectionsdauer unterworfen. Dazu waren 500 grm Formalin, 750 grm Wasser und $250 \mathrm{grm}$ Spiritus, zur Paralysirung des Formalingeruches $300 \mathrm{grm}$ Ammoniak und $30 \mathrm{grm}$ Spiritus erforderlich.

Nach Beendigung der Desinfection wurden wieder 4 Objectträger mit $15^{\mathrm{cem}}$ Nährbrühe abgespült und die Spülfüssigkeit auf 3 Meerschweinchen intraperitoneal vertheilt.

Aus der folgenden Tabelle IX erhellt, dass eine sichere Abtödtung der in den Stäubchen enthaltenen Tuberkelbacillen erfolgt war.

Bei einem zweiten Versuche wurde die Desinfectionsdauer auf 2 Stunden abgekürzt mit entsprechender Erhöhung der Formalinmenge u. s. w. Es wurde für denselben Raum von $15^{\mathrm{cbm}} 800 \mathrm{grm}$ Formalin, 600 grm .Wasser und $300^{\mathrm{grm}}$ Spiritus, ferner $500^{\mathrm{grm}}$ Ammoniak und $50 \mathrm{grm}$ Spiritus verwendet.

Wie die Tabelle $\mathbf{X}$ zeigt, entsprach der Ausfall des Versuches den gehegten Erwartungen. 


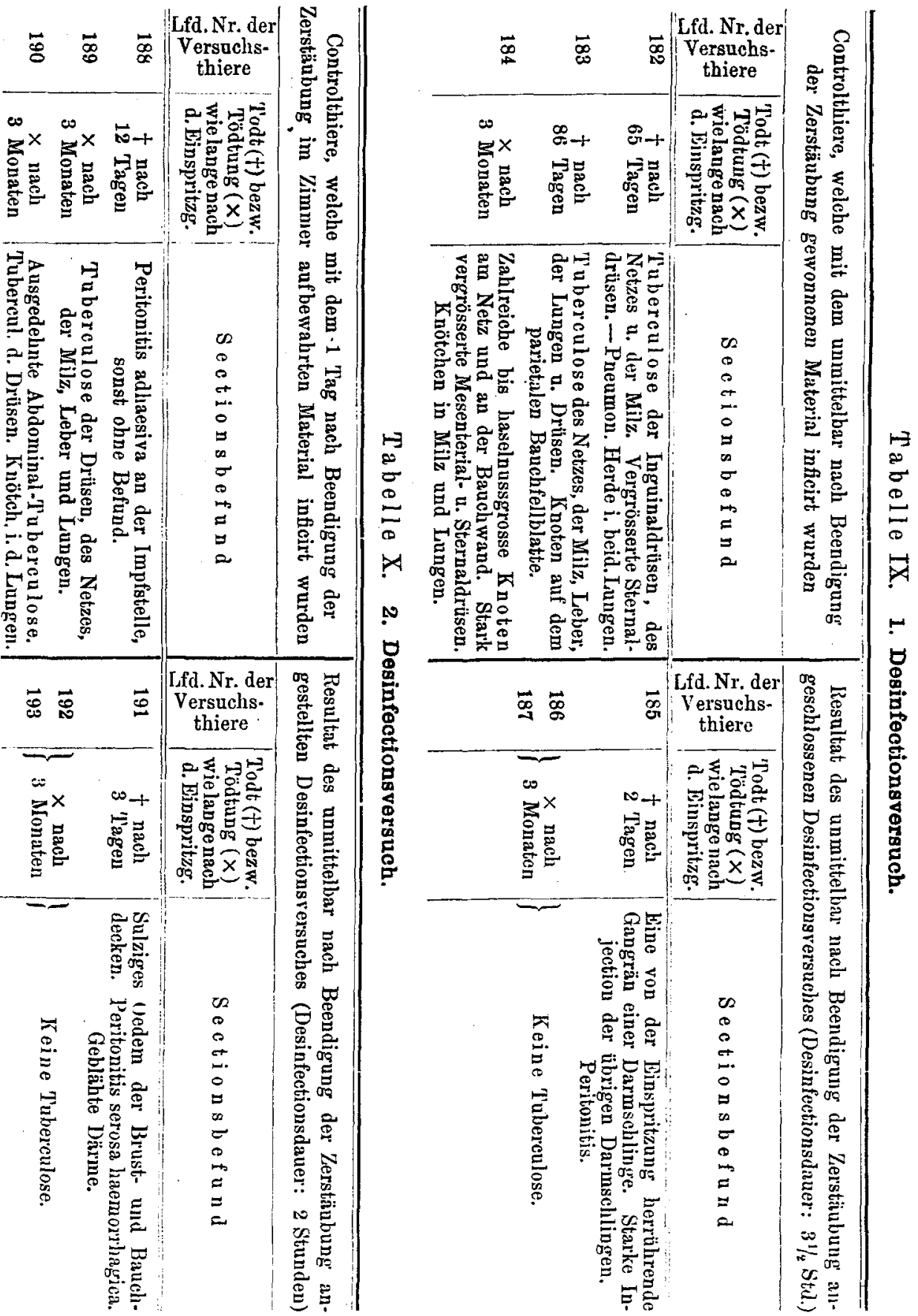




\section{Zusammenfassung und Schlussbemerkungen.}

Am Schlusse meiner oben citirten Arbeit, welche sich hauptsächlich mit der Dauer der Lebensfähigkeit von mit feinsten Tröpfchen verspritzten pathogenen Bakterien beschäftigte, glaubte ich auf Grund einiger Befunde einer relativ längeren Lebensdauer von Prodigiosus und Staphylokokken in Staub- als in Tröpfchenform zu der Annahme berechtigt zu sein, dass die Tuberkelbacillen in den aus trockenen Sputummassen hervorgegangenen Stäubchen ihre Lebensfähigkeit länger bewahren, als wenn sie mit feinsten Tröpfchen versehleppt wurden.

Die damalige Versuchsanordnung war jedoch nicht derart, dass gröbere, nicht flugfähige Stäubchen mit Sicherheit ausgeschaltet wurden. Durch die oben beschriebene, im hiesigen Institut getroffene Versuchsanordnung konnte der flugfähige Staubantheil, in einfacher Weise von dem übrigen getrennt, zur Untersuchung gelangen.

Die nunmehr zum Abschluss gebrachten Versuche, welche, soweit sie flugfähige Stäubchen betreffen, in folgender Tabelle Nr. XI übersichtlich zusammengestellt sind, entsprachen indess nicht ganz der früheren Auffassung.

Tabelle XI.

Dauer der Lebensfähigkeit von Tuberkelbacillen an bezw. innerhalb flugfähiger Stäubchen.

\begin{tabular}{|c|c|}
\hline drt des Staubes & $\begin{array}{l}\text { Zeitpunkt des Absterbens der an flug- } \\
\text { fähigen Stäubchen haftenden Tuberkel- } \\
\text { bacillen nach der Zerstäubung }\end{array}$ \\
\hline $\begin{array}{l}\text { Mit feinsten taberkelbacillenhaltigen } \\
\text { Tröpfchen inficirter Actenstaub. }\end{array}$ & Zwischen 8 und 14 Tagen. \\
\hline Tuberkelbacillenhaltiger Sputumstanb. & Zwischen 4 und 7 Tagen. \\
\hline Tnberkelbacillenbehaftete Kleiderfasern. & Zwischen 5 und 10 Tagen. \\
\hline Tuberkelbacillenbehafteter Strassenstaub. & Zwischen 3 und 8 Tagen. \\
\hline
\end{tabular}

Die Versuche haben also das überraschende Ergebnis gehabt, dass die Lebensdauer der Tuberkelbacillen innerhalb bezw. an flugfähigen Stäubchen eine zieznlich engbegrenzte ist.

Es ist jedoch zu bedenken, dass sich die gefundenen Werthe auf die im diffusen Tageslicht gehaltenen Stäubchen beziehen, für die wenig belichteten bezw. in. dunklen Räumen befindlichen Stäubchen ist eine entsprechend längere Lebensdauer der daran haftenden Tuberkelbacillen

"Die „linlss" stehende Zahl bedeutet noch positives, die ,rechts" stehende dagegen negatives Resultat beim Thierversuch. 
anzunehmen, wie dies ja bereits für die mit feinsten Tröpfchen verspritzten im Kellerdunkel gehaltenen Tuberkelbacillen von mir nachgewiesen ist.

Von grossem Interesse ist die Thatsache, dass diejenigen Stäubchen am lāngsten lebensfähige Tuberkelbacillen aufwiesen, welche vermittelst feinster Tröpfchen damit behaftet wurden. Durch diesen Befund gewinut die Frage der "Tröpfcheninfection" durch die mögliche Combination einer secundären Stäubcheninfection noch eine besondere bisher nicht gewürdigte Bedeutung.

Seither nahm man an, dass die Tuberkelbacillen, welche durch beim Husten u. s. w. verspritzte Tröpfehen ausgestreut wurden, nach ihrem Niederfallen nicht mehr die Gefahr der Luftstaubinfection böten. Dies ist sicherlich zutreffend, wenn die Bacillen mit den Tröpfchen auf blanke Flächen aufgefallen waren, an denen sie je festhaften, nicht aber, wenn sie, wie in unseren Versuchen, auf feinste flugfähige Stäubchen trafen.

Das letztere dürfte unter praktischen Verhältnissen nicht selten vorkommen.

Von diesem Gesichtspunkte aus erfahren auch manche positiven Resultate bei Staubentnahmen in Privatzimmern und Krankensälen ron Phthisikern eine andere Beleuchtung.

Unter den positiven Staubproben, die dabei von den Autoren gefunden wurden, dürfte sich wohl auch die eine oder andere befinden, welche auf die geschilderte Weise secundär zum Träger von Tuberkelbacillen geworden ist.

Wie die Tabelle Nr. XI lehrt, wurde für die Tuberkelbacillen in flugfähigen Sputumstäubchen, an flugfähigen Kleiderfasern und Strassenstäubchen eine geringere Dauer der Lebensfähigkeit als an den durch Tröpfchen inficirten Stäubchen constatirt.

Das erilärt sich wohl so, dass die meisten Tuberkelbacillen unter dem Einflusse der vorausgehenden nothwendigen Trocknung und der Zerkleinerung ihres Vehikels stark geschädigt werden.

Unter den flugfähigen, durch mechanische Zertrünmerung hervorgegangenen infectiösen Stäubchen haben die ron Sputum beschmutzter Kleidung und Taschentüchern herrührenden feineren Faserstäubchen noch mit am längsten lebensfähige Tuberkelbacillen gezeigt. Es sind dies gerade jene Stäubchen, welche durch eine lange Schwebedauer ausgezeichnet sind.

Die beschriebenen Versuche sind also dazu geeignet, darzuthun, dass die Cornet'sche Lehre von der Gefährlicbkeit des Sputumstaubes gewisse weitere Einschränkungen erfahren muss, und dass man den Infectionsmodus dureh verspritzte Tröpfchen - wenigstens bei der auf Luftinfection beruhenden Verbreitungsart der Phthise - für den bedeutungsvolleren wird halten müssen. 